\title{
PolíticAs PARA A EDUCAÇÃo ESPECIAL E AS FORMAS ORgANIZATIVAS DO TRABALHO PEDAGÓGICO
}

\author{
Policy FOR SPECIAL EDUCATION AND ORGANIZATIONAL FORMS OF \\ PEDAGOGICAL WORK
}

\author{
Rosalba Maria Cardoso GARCIA ${ }^{1}$
}

RESUMO: o artigo apresenta reflexões acerca das proposições sobre formas organizativas do trabalho pedagógico nas políticas para a educação especial e referencia-se em análise documental, por meio da qual busca-se apreender os significados dos discursos políticos e as concepções que os sustentam. As fontes principais analisadas são aquelas representativas das Diretrizes Nacionais para a Educação Especial na Educação Básica (Resolução CNE/CEB 2/2001 e Parecer CNE/CEB 17/2001). As ponderações possíveis acerca do tema remeteram para a compreensão segundo a qual as formas organizativas do trabalho pedagógico nas políticas vigentes para a educação especial apóiam-se em dois eixos: 1) uma abordagem educacional para a educação especial, cujo pilar é a concepção de necessidades educacionais especiais em contraposição ao trabalho pedagógico tradicional que tomava como referência o modelo médico-psicológico e 2) uma crítica à homogeneização da escola regular, na defesa de um trabalho pedagógico com referência na diversidade e no reconhecimento das diferenças. O estudo permitiu perceber a insuficiência das proposições inclusivas para as políticas de educação especial no Brasil no sentido da superação das desigualdades educacionais. Esta posição expressa, em grande medida, uma reprodução em relação às proposições internacionais, mas expressa também uma apropriação e preservação ativa de princípios conservadores na compreensão das relações sociais, as quais subordinam, em grande medida, as formas organizativas do trabalho pedagógico no campo em análise.

PALAVRAS-CHAVES: trabalho pedagógico; política educacional; educação especial.

\begin{abstract}
: the paper reflects on special education policies propositions as to the organizational planning involved in pedagogical work. References are drawn from documental analysis, through which we seek to understand the meaning of political discourse and the conceptions that sustain them. The principal sources analyzed are those representative of the National Guidelines for Special Education in Basic Education (Resolution CNE/CEB - Conselho Nacional de Educação/Câmara de Educação Básica [National Education Counsel/Basic Education Chamber] 2/2001 and Counsel CNE/CEB 17/2001). Possible reflections concerning the theme under discussion led to understanding that, based on present special education policies, organizational forms of pedagogical work must be founded on two supporting axes: 1) an educational approach to special education, built upon the conception of special educational necessities in opposition to traditional pedagogy, which used the medical-psychological model as its main reference and 2) criticism of the homogenized regular school, furthering instead a diversity based pedagogy and acknowledgement of the differences approach. The study enabled us to conclude that there are insufficient inclusive proposals resulting from special education policies in Brazil if our aim is to overcome educational inequalities. This position largely expresses a reproduction of international propositions, but it also expresses an active appropriation and maintenance of conservative principles in the understanding of social relationships, which largely subordinate the organizational forms of pedagogical work in the field under analysis.
\end{abstract}

KEYWORDS: pedagogical work; educational policies; special education.

\footnotetext{
${ }^{1}$ Doutora em Educação, Universidade Federal e Santa Catarina - UFSC - rosalba@ced.ufsc.br
} 


\section{INTRODUÇÃO}

O objeto de atenção das reflexões aqui apresentadas refere-se às formas organizativas do trabalho pedagógico propostas para a educação especial na atual política educacional brasileira. Para tanto, o ponto de partida é um entendimento segundo o qual as formas organizativas do trabalho pedagógico são uma expressão da organização do fazer docente em condições que lhe são dadas. As formas organizativas são compreendidas, nos termos deste estudo, como sínteses concretas dos processos de gestão, financiamento, da organização curricular, das condições do trabalho docente, das possibilidades da relação pedagógica na interação professor/aluno e aluno/aluno, dos processos avaliativos, entre outros elementos fundamentais que dão contornos para a escola. Por outro lado, tais condições compreendem também as concepções que amparam as práticas pedagógicas. Interessa-nos neste trabalho focar as concepções subjacentes às políticas para a educação especial na sua relação com a organização do trabalho pedagógico.

As reflexões aqui oferecidas apóiam-se em análise documental orientada pela compreensão dos discursos políticos na sua relação com as mudanças sociais, num exercício de perceber as "novas" realidades propostas a partir de significações (FAIRCLOUGH, 2001).

Considera-se que as fontes documentais representativas da política educacional expressam o resultado, num tempo e espaço históricos, da disputa e consenso de idéias travadas por diferentes forças sociais. Tais documentos representam a apropriação, por parte de seus formuladores, de um conjunto de pensamentos, políticas, ações vividas pelas distintas populações. Dentre aquilo que já está presente na vida social, os formuladores dessa documentação enfatizam, sublinham, focam algumas práticas e pensamentos, desqualificam, obscurecem e desprezam outros. Assim, as fontes documentais são aqui tomadas como material a ser pesquisado uma vez que possibilitam a compreensão da realidade naquilo que está sendo divulgado como um conjunto de conceitos, concepções, princípios que passam a ser considerados como "propostas", "diretrizes" e "parâmetros". Compartilha-se, portanto, da idéia segundo a qual "o que funciona numa sociedade na perspectiva da linguagem, não é a coisa mas os efeitos imaginários que ela produz" (ORLANDI, 1996, p. 96).

Nessa perspectiva de análise, destaca-se também a importância da compreensão dos sentidos produzidos por um discurso (BAKTHIN, 1997) e da percepção da política como um processo, não como algo já dado, mas altamente dinâmico na relação proposto/vivido (OZGA, 2000).

As fontes documentais principais analisadas neste estudo são aquelas que formalizam e instituem as Diretrizes Nacionais para a Educação Especial na Educação Básica, qual seja, Resolução CNE/ CEB 2/2001 e o Relatório que compõe 
o Parecer CNE/CEB 17/2001. ${ }^{2}$ Como forma de desenvolvimento do debate aqui proposto, outras fontes serão referenciadas, procurando expor sua relação com as idéias das fontes principais.

A análise da documentação referida possibilitou perceber que a organização do trabalho pedagógico na educação especial na educação básica apóiase em duas premissas complementares: a defesa de uma abordagem educacional de atendimento e a crítica à homogeneização da escola do ensino regular. A primeira apóia-se na concepção das "necessidades educacionais especiais" para se contrapor ao modelo médico-psicológico de atendimento aos alunos da educação especial. A segunda premissa completa a primeira e defende o reconhecimento da heterogeneidade dos alunos ao contrapor-se à homogeneização praticada pelas escolas do ensino regular. Outros pontos que atravessam este debate são os "serviços" pedagógicos, os locais de atendimento, as funções da educação especial na educação básica e as propostas de flexibilização e adaptação curriculares.

\section{A defesa de uma Abordagem educacional}

A política de educação especial vigente afirma uma abordagem de atendimento educacional que se paute pelo pedagógico como forma de se contrapor à forma clínica de atuação na educação especial, a qual se baseia no modelo médicopsicológico, centrado na etiologia da deficiência e na descrição e medição da (in) capacidade dos sujeitos (CAMBAÚVA, 1988). Os limites do modelo médicopsicológico no processo educativo estão em tomar as características relacionadas à deficiência como representativas do aluno como um todo - o sujeito é a sua deficiência, e o máximo que se pode esperar é que se adapte a alguns comportamentos considerados adequados à sociedade em que vive. ${ }^{3}$

A crítica a essa abordagem concentra-se sobre o papel que os diagnósticos assumiram, gerando preconceito, estigma e segregação, e sobre as mudanças de comportamento propostas pela psicologia, que contribuíram para que a escolaridade significasse um meio de adaptação do aluno com deficiência à sociedade (CAMBAÚVA, 1988).

Na política atual, uma expressão das tentativas de superação desse modelo de compreensão e das práticas relacionadas à educação especial é a proposição do conceito de necessidades educacionais especiais. ${ }^{4}$ Essa conceituação

\footnotetext{
${ }^{2}$ BRASIL. CONSELHO NACIONAL DE EDUCAÇÃO. CÂMARA DE EDUCAÇÃO BÁSICA. Resolução 2/2001, de 11 de setembro de 2001, que institui as Diretrizes Nacionais para a Educação Especial na Educação Básica. Brasília, 2001a e BRASIL. CONSELHO NACIONAL DE EDUCAÇÃO. CÂMARA DE EDUCAÇÃO BÁSICA. Parecer 17/2001, de 3 de julho de 2001. Brasília, 2001 b.

${ }^{3}$ Para maior aprofundamento ver JANNUZZI, G.M. A educação do deficiente no Brasil: dos primórdios ao início do século XXI. Campinas, SP: Autores Associados, 2004.

${ }^{4} \mathrm{O}$ conceito de necessidades educacionais especiais foi utilizado no Relatório Warnock sobre a educação especial Inglesa, publicado em 1978 (CARVALHO, 2000). No Brasil popularizou-se a partir da divulgação da Declaração de Salamanca (1994).
} 
teria por finalidade retirar o foco dos diagnósticos de deficiência e colocá-lo sobre as necessidades de aprendizagem.

\section{Segundo o Parecer CNE/CEB n. 17/2001,}

Em vez de focalizar a deficiência da pessoa, enfatiza o ensino e a escola, bem como as formas e condições de aprendizagem; em vez de procurar, no aluno, a origem de um problema, define-se pelo tipo de resposta educativa e de recursos e apoios que a escola deve proporcionar-lhe para que obtenha sucesso escolar; por fim, em vez de pressupor que o aluno deve ajustar-se a padrões de "normalidade" para aprender, aponta para a escola o desafio de ajustar-se para atender à diversidade de seus alunos (BRASIL, 2001b, p. 14 - grifos no original).

Retomando o disposto no artigo $5^{\circ}$ da Resolução CNE/CEB 2/2001, que define quem são os alunos com necessidades educacionais especiais, o Parecer CNE/CEB 17/2001 contém uma reflexão acerca da população tradicionalmente atendida pela educação especial:

alunos que apresentam deficiências (mental, visual, auditiva, física/motora e múltiplas); condutas típicas de síndromes e quadros psicológicos, neurológicos ou psiquiátricos, bem como de alunos que apresentam altas habilidades/ superdotação (BRASIL, 2001b, p. 19).

Essa definição está presente no documento Política Nacional de Educação Especial como referente às necessidades educacionais especiais (BRASIL, 1994). Essa categoria foi ampliada na Declaração de Salamanca:

crianças com deficiência e crianças bem dotadas; crianças que vivem nas ruas e que trabalham; crianças de populações distantes ou nômades; crianças de minorias lingüísticas, étnicas ou culturais e crianças de outros grupos ou zonas desfavorecidos ou marginalizados (UNESCO, 1994, p. 17).

Pode ser percebida, nesta última definição, uma preocupação com outras categorias para além da deficiência, altas habilidades e condutas típicas, tais como etnia, classe, enfim, um conjunto representativo dos sujeitos tratados nos debates das políticas públicas pelas denominações "minorias" ou "excluídos".

O Parecer CNE/CEB 17/2001 afirma o conceito de necessidades educacionais especiais como "nova abordagem", capaz de superar o trabalho pedagógico tradicional da educação especial por trabalhar na perspectiva da inclusão. Nesse sentido, estaria havendo uma ampliação da ação da educação especial que agora focaliza

não apenas as dificuldades de aprendizagem relacionadas a condições, disfunções, limitações e deficiências, mas também aquelas não vinculadas a uma causa orgânica específica, considerando que, por dificuldades cognitivas, psicomotoras e de comportamento, alunos são freqüentemente negligenciados ou mesmo excluídos dos apoios escolares (BRASIL, 2001b, p. 19).

Com o argumento de que todos os alunos podem apresentar necessidades educacionais especiais ao longo de seus processos de aprendizagem, o Parecer CNE/CEB 17/2001 enfatiza três grupos, reunindo aqueles que apresentam 
1. [...] dificuldades acentuadas de aprendizagem ou limitações no processo de desenvolvimento que dificultem o acompanhamento das atividades curriculares, compreendidas em dois grupos: 1.1. aquelas não vinculadas a uma causa orgânica específica; 1.2. aquelas relacionadas a condições, disfunções, limitações ou deficiências;

2. Dificuldades de comunicação e sinalização diferenciadas dos demais alunos, particularmente alunos que apresentam surdez, cegueira, surdo-cegueira ou distúrbios acentuados de linguagem, para os quais devem ser adotadas formas diferenciadas de ensino e adaptações de acesso ao currículo, com utilização de linguagens e códigos aplicáveis, assegurando-se os recursos humanos e materiais necessários: 2.1. em face das condições específicas associadas à surdez, é importante que os sistemas de ensino se organizem de forma que haja escolas em condições de oferecer aos alunos surdos o ensino em língua brasileira de sinais e em língua portuguesa e, aos surdo-cegos, o ensino em língua de sinais digital, tadoma e outras técnicas, bem como escolas com propostas de ensino e aprendizagem diferentes, facultando-se a esses alunos e a suas famílias a opção pela abordagem pedagógica que julgarem adequada; 2.2. em face das condições específicas associadas à cegueira e à visão subnormal, os sistemas de ensino devem prover aos alunos cegos o material didático, inclusive provas, e o livro didático em Braille e, aos alunos com visão subnormal (baixa visão), os auxílios ópticos necessários, bem como material didático, livro didático e provas em caracteres ampliados.

3. Altas habilidades/superdotação, grande facilidade de aprendizagem que os leve a dominar rapidamente os conceitos, os procedimentos e as atitudes e que [sic], por terem condições de aprofundar e enriquecer esses conteúdos, devem receber desafios suplementares em classe comum, em sala de recursos ou em outros espaços definidos pelos sistemas de ensino, inclusive para concluir, em menor tempo, a série ou etapa escolar (BRASIL, 2001b, p. 19).

Cumpre chamar a atenção para o fato de que os documentos aqui analisados apresentam uma compreensão de educação escolar como uma prática social satisfatória que, atualmente, amplia seu foco para aqueles alunos que até então não seriam capazes de "acompanhar" suas atividades e conteúdos. Pode-se perceber que ocorreu uma inserção nessa categoria de todos aqueles identificados na escola como alunos com "dificuldades de aprendizagem" mesmo que não apresentem um diagnóstico que se baseie em causa orgânica. Ressalto aqui a expressão "acompanhamento das atividades curriculares", da qual se depreende que são alunos considerados com necessidades especiais todos aqueles que não acompanharem o trabalho pedagógico encaminhado na escola regular. Nesse caso, cumpre lembrar o próprio surgimento da educação especial, que se deu relacionado às classificações e seleções dos alunos que não acompanhavam os estudos na escola regular (BUENO, 1993).

Nesse agrupamento de alunos podem estar incluídas todas as “diferenças individuais" tratadas na Declaração de Jomtien (1990) e reforçadas na Declaração de Salamanca (1994).

Nesse sentido, a concepção de necessidades educacionais especiais obscurece as relações de exclusão "na" e "da" escola (FERRARO, 1999) e coloca 
sobre os sujeitos a responsabilidade pelo seu sucesso ou fracasso, à medida que difunde uma idéia de escola democrática e "politicamente correta".

Essa é uma política focalizada em grupos que podem causar "desequilíbrios sociais", generalizados sob o conceito guarda-chuva de "necessidades educacionais especiais", a exemplo do debate crítico oferecido por Challoub (1990), que aborda as "classes perigosas". ${ }^{5}$ Significa que o "todos" da política educacional refere-se àqueles sujeitos que expõem as dificuldades e ineficiência da escola como expressão da participação desigual na sociedade.

Essas reflexões remetem para se pensar que o conceito de necessidades educacionais especiais contribui para racionalizar as "dificuldades individuais", agrupando-as, conforme as análises de Popkewitz e Lindblad (2001), em "categorias de pessoas", para as quais devem ser pensadas políticas "focalizadas".

Segundo os autores, nessa perspectiva articulam-se representações que identificam e ordenam relações, visando a um planejamento social, como no caso de classificações relacionadas a emprego/desemprego, "de risco", etnia e minorias. A categoria "necessidades educacionais especiais" abarca, no campo educacional, as manifestações de desenvolvimento humano identificadas como em situação de "exclusão". Muito embora a educação venha sendo tratada como uma das esferas principais de atuação de políticas de inclusão, pode-se perceber que tais políticas apóiam-se em fundamentos que não superam a responsabilização do próprio sujeito.

Além disso, essa conceituação expressa de maneira ordenada um movimento da realidade captado por alguns autores, tal como Bueno (1993, p. 80), que afirma:

a educação especial, na sociedade moderna, que, na sua origem, absorvia deficiências orgânicas (auditivas, visuais e, posteriormente, mentais), com o desenvolvimento do processo produtivo, foi incorporando população com "deficiências e distúrbios" cada vez mais próximos da normalidade média determinada por uma "abordagem científica" que se pretende "neutra e objetiva", culminando com o envolvimento dos que não têm quaisquer evidências de desvio dessa mesma "normalidade média".

Essa ampliação da "categoria de pessoas" que necessita de medidas especiais de educação caminha pari passu com o acirramento da produção de desigualdades na sociedade capitalista.

Nessa direção, afirma-se que a concepção de necessidades especiais presente na documentação coligida não é suficiente para superar uma abordagem

\footnotetext{
${ }^{5}$ Segundo Challoub (1990), a expressão "classes perigosas", originária na Inglaterra na primeira metade do século dezenove em denominação aos grupos envolvidos com a criminalidade, teria sido apreendida por um funcionário da Polícia de Paris como sinônimo de "classes pobres". Esse segundo significado foi base de discussão na Câmara dos Deputados brasileira nos meses que se seguiram à abolição da escravidão, tendo por objetivo elaborar um projeto de lei para reprimir a ociosidade.
} 
clínica, além de possibilitar o obscurecimento das desigualdades presentes nos processos de aprendizagem vigentes e colocar, mais uma vez, a responsabilidade do sucesso ou fracasso sobre os alunos, individualmente, à medida que contribui para difusão de uma imagem de escola "democrática" e "politicamente correta". Nesse caso, estamos diante de uma diretriz que pode regular as "necessidades básicas de aprendizagem" por baixo, a partir da generalização das condições físicas e psicológicas do sujeito como definidoras de seu processo de aprendizagem (MICHELS, 2000).

Ademais, na política de educação especial na educação básica, a concepção de "necessidades especiais" está sendo usada ora como conceito ampliado que incorpora vários grupos, ora como sinônimo de deficiência. Cumpre, dessa maneira, duas funções: 1) legitimar a política educacional nacional mais ampla ao focalizar a heterogeneidade dos alunos, numa linha discursiva politicamente correta ao abordar a diversidade e 2) valorizar os mecanismos específicos propostos para alunos identificados como deficientes.

Em relação ao segundo item mencionado, importa refletir sobre os "serviços" pedagógicos especializados que devem ser implementados, segundo a política vigente para a educação especial. A diversificação das estratégias propostas contempla desde o atendimento em classe comum do ensino regular até o realizado em escola especial, passando pela classe especial e sala de recursos, bem como pela classe hospitalar e atendimento domiciliar.

Pode-se afirmar que a organização do trabalho pedagógico na proposta de educação especial na educação básica orienta-se pelo local de atendimento: 1 ) na escola regular (classe comum, classe especial e sala de recursos); 2) na escola especial (em seus diferentes níveis de atendimento) e 3) em ambiente não escolar (classe hospitalar e atendimento domiciliar). O local de atendimento mantém íntima relação com as funções que estão previstas para o atendimento especializado: apoiar, complementar e suplementar e, por último, substituir os serviços educacionais comuns. A diversificação do atendimento possibilita contemplar uma grande variedade de necessidades que possam ser apresentadas pela heterogeneidade dos alunos da educação especial.

Outro critério percebido na organização do trabalho pedagógico é o nível de conhecimento a ser trabalhado com cada grupo de alunos. Em relação à classe comum, a proposta política destaca o "significado prático e instrumental dos conteúdos básicos"; para o atendimento em classe especial, o previsto é que, além da flexibilização dos conteúdos, dedique-se atenção às "atividades da vida autônoma e social"; no caso da escola especial, a proposição remete para um "currículo funcional".

Observa-se que, junto ao reconhecimento da heterogeneidade, está estabelecido um sistema hierarquizado entre os diferentes atendimentos ofertados: aos alunos da classe comum, os conteúdos básicos; aos alunos da classe comum com necessidades especiais, os conteúdos básicos em seus "significados práticos e 
instrumentais"; aos alunos das classes e escolas especiais, um descenso dos conteúdos básicos em direção aos autocuidados (higiene, vestuário, alimentação, deslocamento etc). Dessa maneira, pode-se afirmar que as proposições de políticas inclusivas para a educação especial prevêem, para os alunos com necessidades educacionais especiais, um acesso de caráter restrito aos conhecimentos historicamente produzidos pela humanidade. Uma expressão disso é a noção de "flexibilização curricular", a qual pode ter conotações de se contrapor a uma escola seriada, rígida em sua estrutura e "enciclopédica", ou de ser contra desempenhos massificados dos alunos, mas que também pode ser lida como incentivo à redução dos conteúdos a serem apreendidos, conforme as condições individuais dos alunos com necessidades educacionais especiais.

Ao procurar apreender as referências deste debate na política de educação especial brasileira, percebeu-se que essa questão está presente nos Parâmetros Curriculares Nacionais (PCN): adaptações curriculares - estratégias para a educação de alunos com necessidades educacionais especiais (BRASIL, 1998). No debate internacional, a Declaração de Salamanca (UNESCO, 1994) também propunha a "flexibilidade curricular".

Segundo os PCNs, a educação dos alunos com necessidades educacionais especiais deve contemplar as "diferenças individuais" (BRASIL, 1998, p. 18), e "requerer um tratamento diversificado dentro do mesmo currículo" (BRASIL, 1998, p. 24). Essas indicações dão margem a que se pense em recursos e métodos diversificados para o trabalho pedagógico, com a criação de alternativas nos processos de aprendizagem. Contudo, o debate sobre currículo avança no sentido de restringir o que deve ser apreendido: "eliminação de conteúdos básicos do currículo" (BRASIL, 1998, p. 38) e "eliminação de objetivos básicos - quando extrapolam as condições do aluno para atingi-lo, temporária ou permanentemente" (BRASIL, 1998, p. 39).

A referência está colocada nas condições individuais do aluno para entrar em contato com o currículo. Logo, as necessidades especiais estão sendo compreendidas não como estratégias alternativas e criativas que possam ser propostas aos processos de ensinar e aprender, mas como o conjunto de condições que o aluno apresenta. Ou seja, ainda que de maneira descritiva trata-se de um diagnóstico seguido de um prognóstico curricular, uma vez que "conteúdos básicos" permanecem ou são eliminados segundo as "diferenças individuais". Estas últimas constituem a base de análise para a definição de reduções para as aprendizagens escolares dos alunos com necessidades especiais. Retomando o texto do Parecer CNE/CEB n. 17/2001, ali se encontra que o desafio que se apresenta às escolas é "ajustar-se para atender à diversidade de seus alunos" (BRASIL, 2001b, p. 14). O modo como se vislumbra esse "ajuste" é por uma gestão das aprendizagens.

Essa compreensão sobre o trabalho pedagógico apóia-se também em documento curricular já citado, o qual propõe contornos de pensamento único, conferindo às políticas educacionais de inclusão uma certa fatalidade: 
embora muitos educadores possam interpretar essas medidas como "abrir mão" da qualidade de ensino ou empobrecer as expectativas educacionais, essas decisões curriculares podem ser as únicas alternativas possíveis para os alunos que apresentam necessidades especiais como forma de evitar a sua exclusão (BRASIL, 1998, p. 38 - grifos no original).

A restrição dos conteúdos a serem apreendidos remete para práticas históricas da educação especial em relação aos seus alunos, práticas essas também utilizadas com crianças e jovens dos setores populares. Ressalta-se, portanto, a incorporação no plano formal daquilo que já estava presente nas práticas sociais.

Todavia, esses empobrecimentos referentes ao ensino na educação especial podem ser observados com maior ênfase naquilo que tem sido denominado por "currículo funcional", o qual não leva em conta aprendizagens acadêmicas:

Alguns alunos com necessidades especiais revelam não conseguir atingir os objetivos, conteúdos e componentes propostos no currículo regular ou alcançar os níveis mais elementares de escolarização. Essa situação pode decorrer de dificuldades orgânicas associadas a déficits permanentes e, muitas vezes, degenerativos que comprometem o funcionamento cognitivo, psíquico e sensorial, vindo a constituir deficiências múltiplas graves. [...] Alguns programas, devido à expressividade das adaptações curriculares efetuadas, podem ser encarados como currículos especiais. Comumente, envolvem atividades relacionadas ao desenvolvimento de habilidades básicas; à consciência de si; aos cuidados pessoais e de vida diária; ao treinamento multissensorial; ao exercício da independência e ao relacionamento interpessoal, dentre outras habilidades adaptativas (BRASIL, 1998, p. 53).

A política de educação especial brasileira, que se articula numa perspectiva inclusiva, tem como um de seus pressupostos a restrição dos conteúdos básicos da educação básica para os alunos com necessidades especiais. Isso não inclui apenas aqueles identificados como alunos com deficiência, mas todos os que sejam reconhecidos como alunos com "dificuldades de aprendizagem".

Isso pode significar uma minimização das aprendizagens propostas para grande parte dos alunos, na direção de um empobrecimento dos conteúdos a serem trabalhados na educação básica, envolvendo questões como a distorção idade/série, evasão e repetência, aceleração de aprendizagem, entre outras. Tais proposições políticas, contudo, vem ganhando uma aura inovadora e progressista, uma vez que estão apoiadas em discursos que afirmam a importância da diversidade e do reconhecimento às diferenças.

Tais idéias sobre a organização do trabalho pedagógico firmaram-se nos últimos anos como hegemônicas, podendo ser percebidas, mais recentemente, em documento divulgado pela Unesco (2004), intitulado Temário Aberto sobre Educação Inclusiva. Esta fonte é apresentada como uma referência para a implementação de políticas de inclusão educacional. Este material contém uma defesa veemente da idéia de flexibilidade curricular, enfatizando os seguintes aspectos: "flexibilizar as posturas mais rígidas" (p. 29); "flexibilizar procedimentos e práticas" (p. 30); "trabalhar com modalidades mais flexíveis que conduzam à 
titulação ou certificação" (p. 44); "materiais flexíveis" (p. 52); "avaliação flexível" (p. 61); "matrícula flexível" (p. 80); "serviços flexíveis" (p. 81); "estrutura curricular mais flexível para que todos os alunos tenham acesso" (p. 105); "flexibilidade para adaptar o processo de aprendizagem à necessidade de cada estudante" ( p. 108).

A idéia de flexibilidade curricular também é central na proposta de organização do trabalho pedagógico da Secretaria de Educação Especial - SEESP do Ministério da Educação - MEC, a qual pode ser percebida no Documento subsidiário à política de inclusão (BRASIL, 2005). Dois são os aspectos que podem ser destacados desta compreensão: 1) a flexibilidade curricular é considerada fundamental para o processo de inclusão educativa e deve ser pensada a partir do grupo de alunos e a diversidade que o compõe e não para alguns alunos isoladamente (BRASIL, 2005) e 2) a flexibilidade curricular pode ser viabilizada a partir de adequações curriculares e adaptações curriculares (BRASIL, 2005).

Ressalta-se, portanto, a manutenção da idéia de flexibilizar e adaptar os currículos, mas agora também associando a noção de adequação curricular. $O$ referente para as ações educacionais, até então, era o aluno individualmente. Agora, embora ainda tenhamos a menção a "determinado aluno", a referência parece ser o grupo, levando em conta a diversidade que o compõe. Neste caso, não fica claro se o posicionamento em relação à diversidade parte de uma compreensão ontológica segundo a qual todos os grupos humanos são constituídos pelas características da unidade e da diversidade, ou seja, a diversidade como constituinte mesma do humano, ou se a idéia de diversidade é tomada aqui pela presença dos alunos com necessidades especiais nos grupos. No segundo caso, ainda que não esteja claramente afirmada, a referência para as flexibilizações continua sendo o indivíduo.

As preocupações aqui apresentadas estão relacionadas, em grande medida, aos resultados da proposta de condições de aprendizagem contida nas políticas para a educação especial. Percebe-se como foco a defesa de currículos flexíveis/adaptados/adequados às crianças e às suas necessidades de aprendizagem, assim como a defesa da necessidade de flexibilizar a organização e funcionamento da escola para atender à demanda diversificada dos alunos. Frente às bases teórico-metodológicas das políticas educacionais, apoiadas no liberalismo em sua nova formação, nossas inquietações são compartilhadas com o pensamento que afirma

Relegar para um discreto segundo plano o conteúdo da aprendizagem em nome de um apologético "aprender a aprender" implica conceber o "processo educativo como um processo de interação entre significados subjetivos e individuais em oposição à transmissão de um saber objetivo socialmente construído' [...], a ter como resultado a individualização do conhecimento, a naturalização das desigualdades e a cruel responsabilização do indivíduo por aquilo que suas condições objetivas de vida não lhe permitiram, no que se inclui uma educação escolar de qualidade (MARTINS, 2004, p. 65).

A partir dessas reflexões, retomamos a concepção das "necessidades educacionais especiais" utilizada nos discursos das políticas para a educação 
especial como contraposta à abordagem clínica, deslocando a atenção dos diagnósticos relacionados à deficiência e aos rendimentos dos alunos em testes psicológicos. Contudo, tal enfoque está propondo novos níveis de diagnóstico e prognóstico, baseados na relação entre "diferenças individuais" e "currículo", não superando uma compreensão referenciada no "desvio" e na necessidade de "ajuste" dos alunos à sociedade, mantendo, portanto, suas aproximações com uma visão funcionalista.

Nesse caso, é importante salientar o papel social que é atribuído à educação e sua correspondente organização do trabalho pedagógico sob os auspícios das "necessidades educacionais especiais", qual seja, a tarefa de "técnica social", a quem cabe influenciar o comportamento humano para estar adequado aos padrões vigentes de interação e organização sociais (MANNHEIM, 1979).

\section{A CRítica À hOMOgENEIZAÇÃo NA ORGANIZAÇÃo dA ESCOLA REgUlAR}

A organização do trabalho pedagógico conforme proposto pela política de Educação Especial na Educação Básica tem como segundo eixo uma crítica à homogeneização da escola do ensino regular, seus procedimentos, rituais e expectativas em relação aos desempenhos dos alunos.

Estabelecendo um recorte para o ensino fundamental, cerca de $80 \%$ das escolas brasileiras e das matrículas está no modelo seriado (FREITAS, 2004). ${ }^{6}$ Contudo, a dinâmica do ensino fundamental no Brasil nos últimos anos vem sofrendo algumas mudanças que se caracterizam como possibilidades para a organização escolar. Nessa direção, podem ser ressaltados os ciclos de formação (AZEVEDO , 1999), as classes de aceleração e a progressão continuada (ALMEIDA, 2002).

Os ciclos de formação são alternativas de organização do ensino fundamental que ultrapassam a duração das séries anuais como referência temporal para o ensino e a aprendizagem. Nesse sentido, buscam superar a fragmentação dos processos de aprendizagem ocasionada pela seriação, agindo sobre as trajetórias escolares e sobre o processo de reprovação anual. Além disso, demandam mudanças na concepção de conhecimento, de aprendizagem, da função da educação escolar, e na ocupação do espaço e do tempo escolar (BARRETO e SOUZA, 2004). Os ciclos são concebidos como "um tempo de vivência cultural", identificados com cada etapa da vida (infância, puberdade e adolescência) (BARRETO e SOUZA, 2004).

A escola por ciclos de formação ganhou evidência no Brasil principalmente a partir de São Paulo (1989-1992), Rio de Janeiro (1993-1996 e 1997 2000) com o projeto Multieducação, Belo Horizonte (1993-1996) com a Escola Plural e Porto Alegre (a partir de 1994) com a Escola Cidadã (MOREIRA, 2000). As experiências referidas não expressaram uma unidade em termos teóricos, sofrendo

${ }^{6} \mathrm{O}$ autor citado trabalhou com dados baseados no Censo Educacional de 2002. 
influências de duas tendências pedagógicas, quais sejam, a pedagogia críticosocial dos conteúdos e a educação popular. ${ }^{7}$ Por outro lado, defendiam reformas curriculares que desafiavam o caráter centralizador das propostas do MEC, a partir de estados e municípios que elegeram, naqueles momentos, governantes de oposição ao governo federal.

Embora as quatro experiências municipais tenham mantido obediência às normativas nacionais legais referentes às propostas curriculares, baseavam-se em princípios próprios.

Em São Paulo e Porto Alegre escolheu-se a interdisciplinaridade; em Belo Horizonte, preferiram-se eixos transversais e norteadores; no Rio de Janeiro, os princípios educativos e núcleos conceituais. Escapou-se, assim, da idéia de que uma proposta curricular corresponde a uma lista detalhada de conteúdos, procedimentos e avaliação para todas as escolas. Entendeu-se que essa definição deve ocorrer no âmbito do projeto pedagógico de cada escola, cabendo aos órgãos centrais o estabelecimento dos objetivos gerais norteadores dos projetos. Como se vê, o foco foi mais na integração de conhecimentos localmente escolhidos que no saber sistematizado universal, defendido pela pedagogia dos conteúdos (MOREIRA, 2000).

Mais ao final da década de 1990, o município de Belém (PA) implantou o projeto Escola Cabana, caracterizado como uma proposta de ciclos de formação interdisciplinares que, como as anteriores, pretendia superar a estrutura disciplinar, gradual e seriada da escola. A organização escolar por ciclos surge como possibilidade de produção de uma escola menos seletiva, excludente e autoritária, baseando-se numa gestão democrática, em avaliação processual e emancipatória em oposição à visão classificatória, burocrática e aferidora em relação à aprendizagem e na formação continuada dos professores. Contudo, uma realidade em todas estas experiências tem sido a não superação da organização disciplinar do conhecimento, a despeito dos esforços realizados na busca de estratégias com esta finalidade (eixos transversais, complexos temáticos, temas geradores, princípios educativos e núcleos conceituais, entre outros).

As escolas por ciclos deslocaram o processo de construção curricular dos órgãos centrais das redes de ensino para o seu âmbito ao adotarem práticas de tomadas de decisão envolvendo docentes, estudantes e pais. Tal modelo tem como pressuposto que as organizações escolares são construções sociais e uma orientação curricular baseada nos processos concretos presentes no interior da escola, em outros termos, um currículo em ação. Se por um lado eles representam um investimento pedagógico nas aprendizagens dos alunos e no combate à retenção e à evasão escolar, por outro tem sido articulados às finalidades de ampliar o número de alunos no ensino fundamental, e melhorar o fluxo escolar, numa incorporação à lógica gerencial.

\footnotetext{
${ }^{7}$ A primeira tendência pedagógica tem como principais representantes José Carlos Libâneo e Dermeval Saviani. A segunda está relacionada às contribuições de Paulo Freire.
} 
As classes de aceleração consistiram também em formas diferenciadas de organizar o trabalho pedagógico, implantadas a partir de 1996 em alguns estados do país para corrigir a trajetória escolar de alunos em condição de defasagem idade/ série (ALMEIDA, 2002). Contudo, alguns estudos têm mostrado ser esta uma forma organizativa do trabalho escolar que atende à diversidade dos alunos pela manutenção das desigualdades educacionais, embora contribua para a correção, ainda que parcial, dos fluxos escolares (BAHIA, 2004; HANFF; BARBOSA; KOCH, 2002).

Outra estratégia de liberalização dos fluxos escolares é a progressão continuada, identificada com uma base economicista uma vez que internaliza os custos educacionais (FREITAS, 2004). ${ }^{8}$ Apóia-se na garantia das aprendizagens para todos os alunos, a partir do reconhecimento dos diferentes ritmos e do favorecimento da aprendizagem com "ajudas" necessárias (materiais e métodos apropriados). Embora possa parecer, não se contrapõem à seriação, mas limita o poder de reprovação da avaliação formal ao final de cada série (FREITAS, 2004). Mas, mesmo que a progressão continuada elimine a reprovação pelos processos formais de avaliação, ela não elimina do cotidiano escolar os processos de avaliação informal, a partir dos quais são produzidas "trilhas de progressão diferenciadas", expressando uma exclusão por dentro do sistema. Nesse processo, a exclusão é internalizada, pois os alunos permanecem na escola ainda que sem desenvolver as aprendizagens esperadas, ao contrário de quando se evadiam da escola pelo processo de reprovações sucessivas.

As escolas por ciclos, as classes de aceleração e a progressão continuada nas escolas seriadas das redes de ensino do sistema educacional brasileiro, a partir da década de 1990, são expressões da diferenciação dos processos de organização escolar, num esforço de atender às demandas de reconhecimento da heterogeneidade dos alunos, de assumir a diversidade e o respeito às diferenças como uma referência para o trabalho pedagógico.

Tais elementos da escola estão previstos para o nível de Ensino Fundamental. Contudo, sobre essas formas de organização, um outro patamar de propostas são previstas, voltadas para a modalidade Educação Especial. A proposta de educação especial na educação básica traz consigo um conjunto de flexibilizações e adaptações curriculares relacionadas a métodos e recursos diferenciados, mas explicita que também os conteúdos podem ser diferentes (reduzidos) com base nas condições individuais dos alunos. Tais afirmações são feitas em nome de atender à diversidade dos alunos.

Contudo, a proposta de aprendizagem na educação básica como um todo, na atualidade, ao mesmo tempo que advoga o reconhecimento da

\footnotetext{
${ }^{8}$ A progressão continuada foi incorporada pela reforma educacional dos anos 1990 no Brasil, mas não representa uma prática nova, já tendo sido utilizada em outros momentos da história da educação brasileira como estratégia de liberalização dos fluxos escolares.
} 
heterogeneidade de seus alunos, restringe a educação básica a conhecimentos básicos - as "necessidades básicas de aprendizagem" (NEBAS). Segundo Arroyo (1997, p. 19), "as crianças das camadas populares são colocadas em condições de instrução menos exigentes [...]; os conteúdos são reduzidos ao mínimo; o currículo é adaptado às suas "condições'". Essa passagem corrobora a interpretação de que a política educacional recente trabalha com o pressuposto liberal de que alguns alunos apresentam "condições" de aprendizagem limitadas. Assim, para alguns alunos com necessidades especiais são oferecidas as "aprendizagens básicas"; para outros, apenas atividades da vida autônoma e social (AVAS).

A política de educação especial numa perspectiva inclusiva, conforme a análise documental desenvolvida, se constitui de parâmetros classificatórios, meritocráticos, cujos processos participam na definição de forma e quantidade em relação às aprendizagens dos alunos, diferenciando por conseqüência quem pode aprender mais e menos. Os princípios liberais que sustentam essa compreensão de desenvolvimento se apóiam no reconhecimento da diferença, na dignidade humana, na promoção da cidadania (BRASIL, 2001b). Mas é possível perceber nesses propósitos a marca da desigualdade, embora constituída de encaminhamentos "politicamente corretos". O discurso da diversidade, ao mesmo tempo que chama a atenção para o direito à educação dos sujeitos "excluídos", está a serviço de um acesso desigual à cultura humana. Os processos de democratização do acesso que estão sendo propostos operam por meio de seleção e diferenciação internas aos sistemas de ensino e às escolas. Além disso, tais processos são encaminhados sem culpa, uma vez que a avaliação final em relação aos desempenhos escolares, nesses termos, deve ocorrer na vida extra-escolar.

A política educacional tem vinculações com um empobrecimento curricular que se opõe ao que seria necessário em termos de aprendizagens que visem ao desenvolvimento humano. Sua filiação às bases liberais e economicistas remete para a lógica do custo-benefício, segundo a qual a educação é permeada pela valorização do menor gasto com maior eficiência. Apesar disso, a perversidade dessas políticas não está apenas em discriminar sujeitos, mas em lhes atribuir a responsabilidade pelas suas necessidades de aprendizagem, pelo seu fracasso, pelo seu descarte frente às condições globalizadas do mercado.

A política de educação especial na educação básica propõe uma série de medidas para prover os atendimentos educacionais especializados para alunos considerados com deficiência. Por um lado, tais medidas aparentam favorecer o desenvolvimento humano e trazer uma nova abordagem para a educação. Por outro, pode-se produzir outras reflexões sobre essas propostas pedagógicas.

Hoje o acesso ao ensino fundamental está praticamente assegurado a todas as crianças e jovens em nosso país. No entanto, a abertura da escola não veio acompanhada de transformações capazes de alterar suas formas de organização e funcionamento, de assegurar condições de trabalho, salário e formação dos professores, comprometendo sua mudança qualitativa. A permanência na 
escola graças apenas à ausência de reprovação ao longo do ensino fundamental não está assegurando aos alunos uma aprendizagem efetiva. A manutenção das práticas educativas, da estrutura e da cultura tradicionais faz com que a escola ofereça um ensino aligeirado, contribuindo para preservar a situação de exclusão vivida pelos segmentos menos favorecidos economicamente (ALMEIDA, 2002, p. 63).

A política que institui a educação especial sobrepõe, aos mecanismos já existentes na educação básica, outros mecanismos específicos para os alunos com deficiência. As metodologias e recursos diferenciados podem ampliar as possibilidades da relação pedagógica, mas as flexibilizações e adaptações curriculares que levem em conta o "significado prático e instrumental dos conteúdos básicos" também podem nortear o processo ensino e aprendizagem para um empobrecimento curricular e um rebaixamento das exigências escolares. Neste último caso, vislumbram-se tais conseqüências para toda a educação básica e não somente sobre os alunos com necessidades educacionais especiais, com um recuo em relação aos conteúdos considerados mais acadêmicos.

Um outro argumento que tem sido favorável a uma perspectiva inclusiva na educação básica é aquele segundo o qual a presença de "alunos diferentes" em sala de aula deve repercutir em benefícios para as aprendizagens de todos. E, nesse caso, a política educacional convoca as escolas e suas comunidades a proverem adaptações que são necessárias para receber tais alunos. Essa questão remete para a "reestruturação" das escolas e permite pensar que os aspectos considerados como necessitando ser modificados na escola regular para que se torne inclusiva seriam apenas aqueles relacionados às diferenças individuais, não sendo preciso operar outras mudanças, apenas "ajustes" a esses alunos. As escolas inclusivas seriam definidas, assim, pela presença desse tipo de investimento. Segundo o Parecer, devem ainda prever, em seu projeto pedagógico, ações que favoreçam a interação social e sua opção por práticas heterogêneas. Isso permite inferir que nem todas as escolas de uma rede de ensino precisam ser inclusivas, $o$ que remete para um novo nível de flexibilização do trabalho pedagógico.

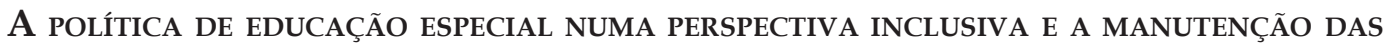 DESIGUALDADES EDUCACIONAIS}

A política educacional brasileira apóia-se no discurso da educação inclusiva, especialmente no que tange à educação básica. Contudo, os mecanismos de que dispõe para evitar e minimizar a "exclusão" escolar não superam os elementos que geram a desigualdade educacional relacionados a ensinar e aprender que, por sua vez, estão vinculados à dinâmica social vigente.

As medidas para conter a evasão e a repetência escolar contribuem para melhorar a gestão educacional, uma vez que operam sobre os fluxos de entrada e saída dos alunos, aumentam o registro de alunos vinculados à educação básica, o que justifica os investimentos financeiros declarados pelos governos (FREITAS, 
2002). A exclusão escolar tem um custo, pois os alunos abandonam e retornam muitas vezes, interrompem uma série, gerando a necessidade de criar programas que corrijam esses fluxos, como por exemplo àqueles relativos à aceleração de aprendizagem para minimizar a defasagem idade/série. As medidas inclusivas criam uma possibilidade de ampliar o controle sobre essa dinâmica, esse "metabolismo" escolar, resultando, segundo a lógica das políticas em foco, em melhoria na gestão do sistema educacional.

Em relação aos alunos com deficiência, a articulação da educação especial à educação básica também cumpre essa função de racionalizar o custo de uma série de "serviços educacionais especializados", muitos dos quais realizados por instituições privado-assistenciais financiadas pelo Estado (SILVA, 2000), uma vez que esses alunos passam a ser "computados" pelo sistema de ensino.

As reflexões aqui apresentadas acerca das políticas educacionais perseguem uma perspectiva de produção de experiências escolares que levem em consideração a singularidade dos indivíduos, as diferenças concretas constituintes do ser humano. No debate com as proposições políticas atuais para a educação especial na educação básica, contudo, o discurso da diversidade e do "reconhecimento das diferenças" pode ser apreendido como busca de possibilidades para o desenvolvimento humano, mas também como diferenciação dos modos de fazer parte da escolarização básica. Esta segunda possibilidade, orientada por uma lógica gerencial na abertura da escola do ensino regular à heterogeneidade dos alunos, re-significa as diferenças individuais relacionadas à deficiência como motivo sem culpa da proposição de limites às aprendizagens. As diferenças não são tomadas com o sentido de pesquisar formas diversificadas de possibilitar que os alunos se apropriem da cultura produzida historicamente. E, como se trata aqui de conhecimentos, e não de informações, não é algo que possa ser apropriado individualmente, precisando necessariamente, para ser elaborado, de interações sociais que qualifiquem o desenvolvimento humano.

Afirma-se, portanto, a insuficiência das proposições inclusivas para as políticas de educação especial no Brasil no sentido da superação das desigualdades educacionais. Esta posição expressa, em grande medida, uma reprodução em relação às proposições internacionais (Unesco, 1990; 1994; 1999; 2004), mas expressa também uma apropriação e preservação ativa de princípios conservadores na compreensão das relações sociais, as quais subordinam, em grande medida, as formas organizativas do trabalho pedagógico no campo em análise.

\section{REFERÊNCIAS}

ALMEIDA, M.I. de. Ações organizacionais e pedagógicas dos sistemas de ensino: políticas de inclusão? In: ROSA, D.E.G. e SOUZA, V.C. de. (Org.) Políticas organizativas e curriculares, educação inclusiva e formação de professores. Rio de Janeiro: DP\&A, 2002. p. 57-66. 
ARROYO, M. Fracasso-sucesso: o peso da cultura escolar e o ordenamento da Educação Básica. In: ABRAMOWICZ, A; MOLL, J. (Org.) Para além do fracasso escolar. Campinas: Papirus, 1997.

AZEVEDO, J. C. Escola cidadã: construção coletiva e participação popular. In: SILVA, L.H. da (Org.) A escola cidadã no contex to da globalização. 3. ed. Petrópolis: Vozes, 1999. p. 308-319.

BAHIA, N. Políticas de enfrentamento do fracasso escolar: inclusão ou reclusão dos excluídos? In: REUNIÃO ANUAL DA ANPED, 27., 2004, Caxambu. Anais... Caxambú, 2004. 1 CDROM.

BARRETO, E. S.; SOUZA, S. Z. Ciclos: estudos sobre políticas implementadas no Brasil. In: REUNIÃO ANUAL DA ANPED, 27., 2004, Caxambu. Anais... Caxambú, 2004. 1 CD-ROM.

BAKTHIN, M. Marxismo e filosofia da linguagem. 8. ed. São Paulo: HUCITEC, 1997.

BRASIL. Conselho Nacional de Educação. Parecer 17/2001, de 3 de julho de 2001. Diretrizes Nacionais para a Educação Especial na Educação Básica. Brasília: CNE, 2001b.

BRASIL. Conselho Nacional de Educação. Resolução n. 2, de 11 de setembro de 2001, institui as Diretrizes Nacionais para a Educação Especial na Educação Básica. Brasília: CNE/CEB, 2001a.

Brasil. Ministério da Educação. Documento subsidiário à política de inclusão. Brasília: MEC, 2005.

BRASIL. Ministério da Educação. Secretaria de Educação Especial. Política nacional de educação especial. Brasília: MEC/SEESP, 1994.

BRASIL. Ministério da Educação. Secretaria do Ensino Fundamental. Secretaria de Educação Especial. Parâmetros curriculares nacionais. Adaptações curriculares. Estratégias para a educação de alunos com necessidades educacionais especiais. Brasília: MEC/SEF/SEESP, 1998.

BUENO, J. G. S. Educação especial brasileira: integração/segregação do aluno diferente. São Paulo: EDUC, 1993.

CAMBAÚVA, L. G. Análise das bases teórico-metodológicas da educação especial. 1988. 132 f. Dissertação (Mestrado em Educação)-Pontifícia Universidade Católica, São Paulo, 1988.

CARVALHO, R.E. Removendo barreiras para a aprendizagem: educação inclusiva. Porto Alegre: Mediação, 2000.

CHALlOUB, S. Classes perigosas. Revista Trabalhadores. n. 6. Campinas, SP: Associação Cultural Arquivo Edgar Leurenroth: Unicamp/Secretaria de Cultura de São Paulo, p. 522, 1990.

FAIRCLOUGH, N. Discurso e mudança social. Trad. Izabel Magalhães. Brasília: UNB, 2001.

FERRARO, A. R. Diagnóstico da escolarização no Brasil. Revista Brasileira de Educação, São Paulo, n. 12, p. 22-47, 1999.

FREITAS, L. C. de. A internalização da exclusão. Educação e Sociedade. Campinas, v. 23, n. 80, 2002. 
FREITAS, L. C. de. (Ciclo ou séries?) O que muda quando se altera a forma de organizar os tempos-espaços da escola? In: REUNIÃO ANUAL DA ANPED, 27., 2004, Caxambu. Anais... Caxambú, 2004. 1 CD-ROM.

HANFF, B. B. C.; BARBOSA, R.; KOCH, Z. M. Classes de aceleração: "pedagogia" da inclusão ou da exclusão? Ponto de Vista, Florianópolis, n. 3/4, p. 27-46, 2001/2002.

JANNUZZI, G. M. A educação do deficiente no Brasil: dos primórdios ao início da século XXI. Campinas: Autores Associados, 2004.

MANNHEIM, K. A educação como técnica social. In: PEREIRA, L.; FORACCHI, M.M. (Org.) Educação e Sociedade (leituras de sociologia da educação). 10. ed. São Paulo: Companhia Editora Nacional, 1979. p. 88-90.

MARTINS, L. M. Da formação humana em Marx à crítica da pedagogia das competências. In: DUARTE, N. (Org.) Crítica ao fetichismo da individualidade. Campinas: Autores Associados, 2004.

MICHELS, M. H. Caminhos da exclusão: o portador de necessidades especiais na política educacional nos anos 90. 2000. 99 f. Dissertação (Mestrado em Educação) - Centro de Ciências da Educação, Universidade Federal de Santa Catarina. Florianópolis. 2000.

MOREIRA, A. F. B. Propostas curriculares alternativas: limites e avanços. Educação \& Sociedade, Campinas, v. 21, n. 73, p. 109-138, dez 2000.

ORLANDI, E. P. Discurso\&leitura. 3. ed. São Paulo: Cortez / Campinas: Editora da Unicamp, 1996.

. Análise de discurso: princípios\&procedimentos. Campinas: Pontes, 2001.

OZGA, J. Investigação sobre políticas educacionais: terreno de contestação. Coleção currículo, políticas e práticas. Porto: Porto Editora, 2000.

POPKEWITZ, T.; LINDBLAD, S. Estatísticas educacionais como um sistema de razão: relações entre governo da educação e inclusão/exclusão sociais. Educação e Sociedade. Campinas, v.22, n. 75, p. 111-148, 2001.

SILVA, S. Educação especial: um esboço de política pública. 2000. 183 f. Tese (Doutorado em Educação) - Faculdade de Educação, Universidade de São Paulo, São Paulo. 2000.

UNESCO. Declaração mundial de educação para todos. Plano de ação para satisfazer as necessidades básicas de aprendizagem. Tailândia, 1990.

1994.

. The Salamanca statement and framework for action on special needs education. Spain,

Temario Abierto sobre educação inclusiva. Materiales de apoyo para responsables de políticas educativas. Santiago, 2004.

. Salamanca Cinco Años Después. Una revision de las actividades de Unesco a la luz de la Declaracion y el Marco de Accion de Salamanca. Sección de Necesidades Educativas Especiales. Dirección de Educación Básica. Paris, 1999.

Recebido em 24/08/2006

Reformulado em 28/11/2006

Aprovado em 14/12/2006 